\title{
ERRATUM
}

In: Appl Microbiol Biotechnol, Vol. 42, No. 1, pp. 173-178:

Due to an unfortunate error, the drawings in Figures 3 and 5 of the following contribution have been transposed:

Labare MP, Alexander M:

\section{Microbial cometabolism of sucralose, a chlorinated disaccharide, in environmental samples}

The correct presentations are as follows:

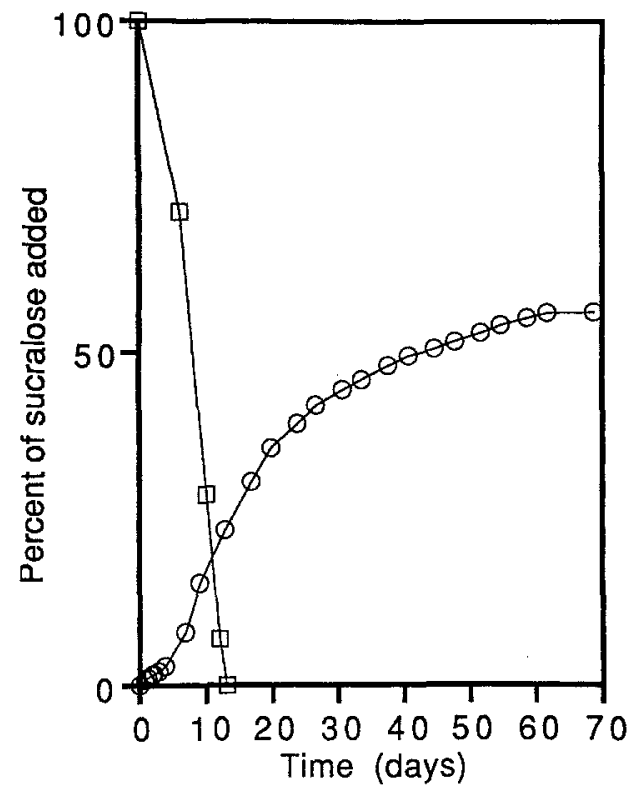

Fig. 3 Sucralose disappearance and mineralization in Lima loam amended with $1.0 \mathrm{~g}$ sucralose $/ \mathrm{kg}$ : $\square$ sucralose, $\mathrm{O}^{14} \mathrm{CO}_{2}$

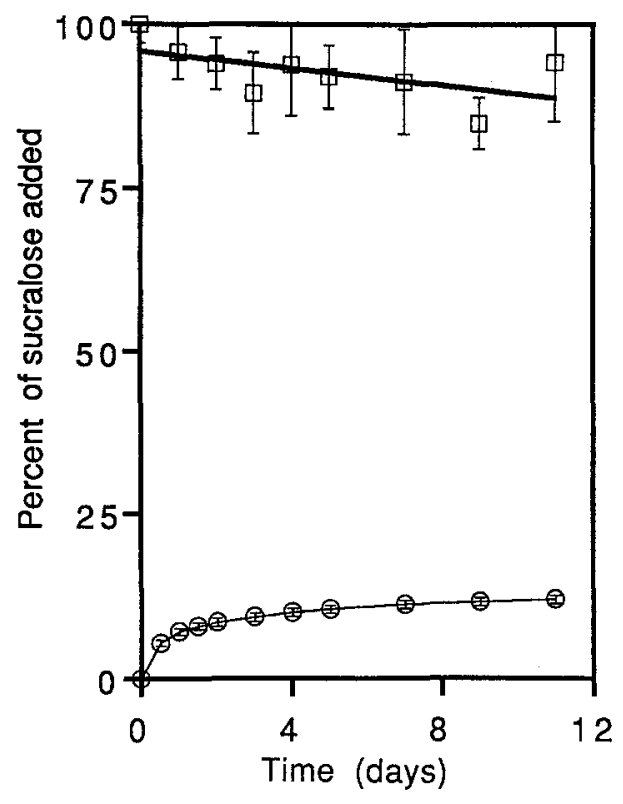

Fig. 5 Disappearance and mineralization in sewage of sucralose added at $1.0 \mathrm{~g} / \mathrm{l}:$ Symbols as in Fig. 3 